\title{
"All behaviour has meaning": A qualitative exploration of dementia training of healthcare assistant students
}

\author{
Tracy M. Christianson*1, Tracy J. Hoot ${ }^{1}$, Victoria McLelland ${ }^{2}$, Kimberly Morris ${ }^{1}$ \\ ${ }^{1}$ School of Nursing, Thompson Rivers University, Kamloops, British Columbia, Canada \\ ${ }^{2}$ Advance Gerontological Education Inc., Hamiliton, Ontario, Canada
}

Received: July 16, 2020

DOI: $10.5430 /$ jnep.v11n2p28

\author{
Accepted: October 8, 2020 \\ Online Published: October 21, 2020
}

URL: https://doi.org/10.5430/jnep.v11n2p28

\begin{abstract}
Statement of the Problem: Nurses face a high level of risk of violence compared with other workers, with higher frequency towards those who are younger and less experienced. Risk of violence is similar for health care aides, and nursing students, with health care aides experiencing the highest rate of injury because much of their work and clinical practice is in long-term care settings where many residents are at risk for challenging behaviours due to cognitive changes. The purpose of this project was to evaluate the effects Gentle Persuasive Approaches(C) (GPA) training had on health care assistant students' knowledge and ability to care for patients who have the potential for responsive behaviours. GPA is a training program recognized in Canada as best practice in the management of responsive behaviours of patients, providing learners with the skills to interact and intervene to diffuse escalating care situations. Methodology: A mixed-methods approach with a quasi-experimental, repeated measures design was used. Health care assistant (HCA) students received GPA training by certified faculty coaches prior to their clinical practice. Repeated measure questionnaires were administered pre-GPA, post-GPA, and post-clinical practice. Focus groups allowed students to reflect on how GPA prepared them for managing responsive behaviours post-clinical practice. Findings: The results demonstrate the effectiveness of offering evidence-based dementia training program while students are still in their educational program to better prepare them to provide person-centred care and keep themselves and their patients safe.
\end{abstract}

Key Words: Nursing student, Dementia, Training, Responsive behaviours, Knowledge, Confidence

\section{BACKGROUND}

People living with Alzheimer's disease and other related dementias experience neuro-degenerative brain changes that result in impaired cognitive functions including memory, judgement, attention, communication, and abilities to complete activities of daily living. ${ }^{[1,2]}$ People living with dementia can also experience behavioural symptoms such as agitation, anxiety, irritability, depression, apathy, disinhibition, hallucinations, and sleep or appetite changes that are often manifested in care settings as repetitive vocalizations, searching, wandering, swearing, striking out, and protesting care. ${ }^{[2,3]}$ These symptoms are referred to as responsive behaviours, as they occur in response to stressful physical or social environments and are an attempt by the resident to communicate about unmet needs. ${ }^{[4]}$ Responsive behaviours are a common occurrence in people living with dementia across all patient care settings in Canada, ${ }^{[5]}$ unfortunately causing a great deal of distress for caregiving staff. ${ }^{[6-9]}$ More-

\footnotetext{
*Correspondence: Tracy M. Christianson; Email: tchristianson@tru.ca; Address: School of Nursing, Thompson Rivers University, Kamloops, British Columbia, Canada.
} 
over, if physically aggressive episodes are not effectively defused, injuries can occur to both caregiving staff and care recipients.

Of all caregiving staff, health care assistants (HCA) encounter the highest rate of injury due to violence in the workplace, often related to the direct care that they provide to people living with dementia and responsive behaviours. ${ }^{[10,11]}$ These injuries can lead to job strain, anxiety, sleep problems, and loss of self-confidence, all of which can lead to decreased work performance for the HCA, resulting in increased errors and patient infection. ${ }^{[10]}$

Health care students are liable to be exposed to or experience residents with more highly escalated responsive behaviours in their clinical practice placements. ${ }^{[12]}$ These experiences can span from verbal attacks to more serious physical assaults, ${ }^{[12,13]}$ with HCAs being the majority of students exposed to these aggressive episodes. ${ }^{[14]}$ Students tend to be more at risk because they are generally younger with less experience or training. ${ }^{[15]}$ When students have such experiences, this can have negative consequences, resulting in physical and psychological trauma, even an abhorrence toward the profession they are training for. ${ }^{[12]}$

A violence prevention program can improve the quality of the workplace and minimize the potential for physical and/or psychological injury ${ }^{[16]}$ and assist healthcare staff to feel more confident in dealing with residents with responsive behaviours in a safe environment, thereby improving care. ${ }^{[17]}$ While training on managing responsive behaviours has been recommended for staff in health care organizations, similar preparation for nursing students has received minimal attention thus far. ${ }^{[10,17]}$ Because of this lack of training, health care students such as those in nursing and HCA programs do not generally acquire the knowledge and skills to manage the responsive behaviours that they may encounter in clinical settings. ${ }^{[18-21]}$

In this paper, we report on the findings of an intervention with HCA students that explored the effects of a standardized evidence-based educational training program intended to improve the students' understanding and confidence in managing responsive behaviours when caring for people living with dementia. The findings are part of a larger study

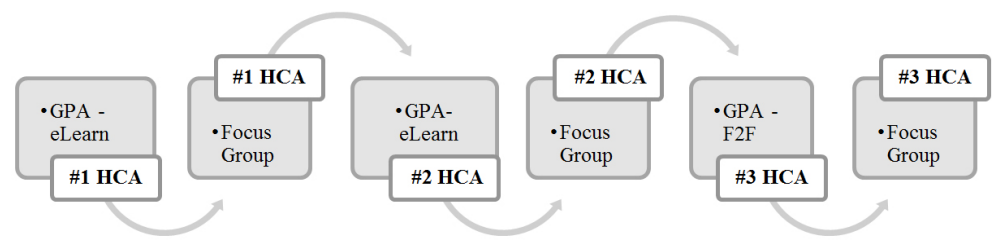

on the use of a standardized educational program for managing responsive behaviours for both HCA and first year undergraduate nursing students.

\subsection{Theoretical framework}

Learners not only must acquire new knowledge, skills, and information but also transform how they think and learn. They come with life and learning experiences and the educator's goal is to help transform learners' existing knowledge. Mezirow's ${ }^{[22,23]}$ transformational learning theory forms the foundation for this research project; using a process of encouraging learners to become critically aware, consider, evaluate, and revise their underlying values, beliefs, and assumptions.

Transformational learning is understood to be a way of using prior understanding to construct new or adapt understanding to make meaning and guide later action. ${ }^{[22,23]}$ In other words, transformational learning allows learners to move from understanding the content to the action of applying that new knowledge.

\section{MethodologY}

\subsection{Sample \& design}

Students $(\mathrm{N}=84)$ in the HCA program at one Canadian university were the target participants for this study during the 2017-2018 academic year. Participants were assigned to one of two learning formats for each of the three $(n=30, n=28$, $\mathrm{n}=26$ ) yearly program cohorts; either completed the training intervention through online eLearning with a two-hour classroom follow-up session or a face-to-face (F2F) 7.5 hour classroom session. Because the F2F intervention training was a mandatory component of the HCA program prior to the study, two of the three cohort groups were assigned to complete the training in the eLearning format with one cohort completing the F2F format (see Figure 1). The rationale was to assess whether one format was more successful in changing students' understanding and confidence in managing responsive behaviours. Regardless of which format students were assigned to, participation in this study was voluntary. All students received the GPA training, but those who chose to participate in the study gave their informed consent to do so. Ethical approval from the University Research Ethics Board was granted prior to the start of this study.

Figure 1. Project sequencing 


\subsection{Intervention}

The educational intervention implemented in this study is Gentle Persuasive Approaches (c) (GPA), an established curriculum developed in 2004 by an interdisciplinary group of educators and clinicians in Ontario, Canada. The GPA curriculum was initially designed to address the learning needs of staff in long term care in the management of behaviours associated with dementia; with the goal to educate staff to use a person-centred approach and respond respectfully, with confidence and skill, to behaviours associated with dementia. ${ }^{[24]}$ The program encourages staff to reframe behaviour traditionally viewed as "disruptive" and "aggressive" so that it is interpreted as self-protective or responsive behaviour that occurs because of unmet physical, psychological, spiritual, or cultural needs. As several studies have shown, staff learned to confidently assess the meaning behind the behaviour while working together with the patient and their family to meet the patient's needs while safely deescalating responsive behaviours. ${ }^{[25-30]}$

\subsubsection{GPA face-to-face}

Gentle Persuasive Approaches in its F2F form, was facilitated by faculty members who were certified as GPA coaches after successful completion of a 2-day training program. The GPA program is divided into 4 modules with content on personcentred care principles (module 1), brain changes common in dementia and delirium (module 2), communication and interpersonal strategies (module 3), and staff-specific selfprotective skills and team/patient/family debriefing and reassurance techniques (module 4). The faculty GPA coaches delivered the program to the designated participants between December 2017 and May 2018. The GPA curriculum was delivered to participants over a 7.5-hour educational day by teams of two certified GPA coaches. The GPA curriculum was comprised of a pre-packaged, scripted program including PowerPoint slides, videotaped vignettes, handson practice, opportunities for reflection and dialogue, and a workbook for each participant. At the conclusion of the program, participants were given a certificate in recognition of their completion of the standardized GPA Program.

\subsubsection{GPA e-learning and follow-up classroom session}

GPA eLearning. The GPA eLearning program was made available to eligible participants through a standardized recruitment message sent to their institutional email address. The recruitment message included a URL hyperlink, where participants created a personal account used to complete the course. The course was available to enrolled participants for a period of four weeks, during which time they could login and complete the course from the location of their choice and as their schedules allowed. The GPA eLearning program takes 2-3 hours to complete and can be taken in discontinuous time periods. The GPA eLearning course contains narrated, standardized slide decks built into the four modules, with white board animations, video clips, matching exercises that review core principles, and instructional GIFs that demonstrate the correct application of appropriate body containment strategies suitable for managing responsive behaviours experienced by older adults. In addition, a portable document format (PDF) version of the workbook was available for download by participants. Upon finishing all four modules of the program, participants could download a generated certificate of completion for their records.

Classroom Follow-Up Session. Approximately one month after the eLearning groups of HCA participants completed the online component of GPA eLearning, they attended a two-hour F2F classroom session, facilitated by faculty GPA certified coaches. The aim of these sessions was to provide the participants with an opportunity to engage in practical applications of the principles learned during the GPA eLearning modules, including practice of the GPA body containment strategies and physical techniques. During the classroom session, student participants took part in interactive group activities, personal case studies, discussions, and roleplaying demonstrations.

\subsection{Data collection}

Pre- and post-GPA intervention, participants were asked to answer three qualitative questions that are included in the "Self-Perceived Behavioural Management Self-Efficacy Profile" (SBMSEP), originally developed and reviewed by clinical experts in the field of dementia behavioural management to establish content validity with a Cronbach $\alpha=$ 0.93. ${ }^{[27,29]}$ Participants were asked how they would describe themselves when providing care to older people who are aggressive, agitated, or upset; what they would want to change in their ability to respond to older persons with responsive behaviours; and what best practice approaches they would use to respond to older people with responsive behaviours. The questions were administered to participants through a secure online survey platform where participants provided anonymous answers pre-GPA and 12 weeks post-completion of their 270-hour clinical practicum.

\section{Focus groups}

All participants in both the eLearning and F2F groups were invited to one of three 60-minute semi-structured focus groups in which they were invited to share their views about how well prepared they felt in the practice setting. Each focus group occurred at the end of each cohorts' 270-hour clinical practice experience; two eLearning groups and one F2F group. A moderator facilitated each focus group while a researcher took notes and voice recorded the discussions. 
Responses were elicited using a guide of open-ended questions with follow-up probes for clarification. Questions were about participants' perceptions of their ability to manage responsive behaviours, their experiences and interactions during their clinical placements, and about the effects of the GPA training on their confidence and competence in such situations.

\subsection{Data analysis}

\subsubsection{Quantitative data analysis}

Demographic Information. Descriptive statistics were summarized for the participants' demographic characteristics (age, sex, previous education, previous dementia training), and these categorical variables were reported as frequencies (see Table 1).

\subsubsection{Qualitative data analysis}

Typed data from the three qualitative survey questions were extracted from the online survey platform. The audiorecorded focus group data were transcribed verbatim. The first two authors independently analyzed the data from the transcripts and the survey questions and compared and confirmed findings to ensure reliability and consistency. ${ }^{[31]}$ Further, validity of this study was established using two data collection methods (pre-/post-GPA questions and focus group) and two sample groups (eLearning and F2F) to help reduce bias. Using two methods of delivery helped to reduce bias toward one type of outcome, increasing validity of the results. The data were then subjected to thematic review and were analyzed using a step-by-step inductive content analysis approach to identify themes and patterns that emerge in the survey qualitative questions and focus groups. ${ }^{[32]}$ This process created an understanding of the experiences and perspectives of HCA students caring for people living with dementia and responsive behaviours.

\section{Results}

\subsection{Demographic information}

Of the 69 participants who elected to participate in the study, nearly all participants provided at least some demographic information. Most of the participants were female and had a similarly wide distribution of ages, ranging from $<19$ to $30+$ years old. Participants generally had either a high school diploma or a prior college diploma as their highest level of education completed to date, although the GPA F2F group had a significantly larger proportion of participants who had completed a college diploma (50\%) than the GPA eLearning group did $(17.4 \%), p<.05)$. Very few participants in either group had any previous dementia education, with over $82 \%$ of participants having had no exposure to dementia education training prior to this intervention other than what they received in their HCA program (see Table 1).

Table 1. Baseline participant demographic characteristics

\begin{tabular}{|c|c|c|c|c|c|c|}
\hline & $\begin{array}{l}\text { HCA GPA eLearning } \\
(n=53)\end{array}$ & $\begin{array}{l}\text { HCA GPA Face to Face } \\
(n=19)\end{array}$ & Missing & $\chi^{2}$ & df & $p$ \\
\hline Age (years) & & & 8 & 6.00 & 4 & .199 \\
\hline$<19$ & $5(10.4 \%)$ & $0(0 \%)$ & & & & \\
\hline $19-20$ & $11(22.9 \%)$ & $2(12.5 \%)$ & & & & \\
\hline $21-24$ & $10(20.8 \%)$ & $3(18.8 \%)$ & & & & \\
\hline $25-30$ & 7 (14.6\%) & $1(6.3 \%)$ & & & & \\
\hline$>30$ & $15(31.3 \%)$ & $10(62.5 \%)$ & & & & \\
\hline Gender & & & 9 & 1.85 & 1 & .174 \\
\hline Female & $42(89.4 \%)$ & $16100 \%)$ & & & & \\
\hline Male & $5(10.6 \%)$ & $0(0 \%)$ & & & & \\
\hline Education & & & 10 & 9.28 & 4 & .054 \\
\hline High School & $31(67.4 \%)$ & $6(37.5 \%)$ & & & & \\
\hline College Diploma & $8(17.4 \%)$ & $7(43.8 \%)$ & & & & \\
\hline Undergraduate Degree & $4(8.7 \%)$ & $2(12.5 \%)$ & & & & \\
\hline Other & $3(6.6 \%)$ & $0(0.0 \%)$ & & & & \\
\hline Previous Dementia Education & $5(10.6 \%)$ & $2(12.6 \%)$ & 9 & 0.72 & 2 & .70 \\
\hline None & $42(89.4 \%)$ & 14 (87.5\%) & & & & \\
\hline
\end{tabular}

\subsection{Qualitative findings}

\subsubsection{Fear of the unknown}

Prior to starting the GPA training, HCA participants were asked to describe the way they respond to older people with dementia who have responsive behaviour and what they thought were best practices in such situations. Most participants described themselves as being calm and patient and 
offered some general strategies for providing care, such as taking their time, stop, be gentle, look for clues, and try to figure things out. However, there was a general concern about the lack of experience and high level of fear and anxiety about participants' ability to care for people with dementia and manage responsive behaviours; represented here as 'Fear of the Unknown'. Many participants highlighted their concerns about the lack of experience. For example, some participants expressed not having any real experience, or wanting to learn more, suggesting that there is a fear of not knowing what to expect or what their responses would be if or when they encounter people with dementia and responsive behaviours. As one participant articulated, "I haven't had enough interactions to say how I am when it comes to these situations" (eLearning Participant).

The 'Fear of the Unknown' was also evident as participants described how they would respond to people with responsive behaviours. Many expressed being fearful, nervous, or scared for example, "I feel I would be fearful at first..." and, "I am usually scared I will cause further aggravation...", and finally, "I'm cautious and patient but I get worried/stressed...." Although participants had little to no experience, they were aware that they should try and discover the reason for a person's agitation. However, they generally did not describe specific strategies they might use to defuse and de-escalate the situation. For example, "I might be a bit concerned but I would try to stay positive", or "... smiling but keeping my distance..." This 'Fear of the Unknown' was made clear when participants described what they would want to change about their current approaches. The majority wanted to change their level of confidence, to gain more experience and expand their knowledge of strategies they could use to prevent or de-escalate responsive behaviours. One participant described that the aspect they wanted to change about their practice was “... to have less fear. I think after I have experience and learn more tools and what works, the fear will be less" (F2F Participant).

\subsubsection{Transformational understanding}

Shortly after completing GPA training, participants spent 240 hours over a 12-week period in clinical placements. At the conclusion of the practicum experiences, the questions asked pre-GPA training were asked again. Also, data were collected from participants in the three focus groups $(n=10$ for each group). Questions focused on their confidence in providing care to a person experiencing responsive behaviours, how they responded to increasing agitation or aggression in people living with dementia, including if and how GPA training prepared them. Overall results from the questions and the three focus groups demonstrated participants' understanding of how GPA had influenced their learning to confidently and competently manage responsive behaviours. Consensus from the participants was that all behaviour has meaning, understanding the underlying meaning of the behaviour is important, and how participants respond and interact with residents can positively impact the interactions, and through de-escalation, participants are able to keep their residents and themselves safe. Themes that became evident from the data were 'All Behaviour has Meaning', 'Knowledge is Power', 'Paying Attention', and 'Labelling Residents'.

\section{1) All Behaviour has meaning}

'All Behaviour has Meaning' was an important theme that arose from the data. Participants demonstrated a clear understanding that responsive behaviours are expressions of unmet needs or the result of environmental triggers. The GPA training provided participants with the theory about cognitive changes in people living with dementia. For example, "I have a better understanding of how dementia affects an individual's brain and behaviors" (eLearning Participant). Understanding why people with dementia act or respond the way they do demonstrated for participants that responsive behaviours were peoples' way of communicating. One participant stated, "Understand the person behind their disease. It is important to listen, acknowledge and validate their feelings and try to understand them at all times what they are trying to communicate" (F2F Participant). While another reported, "Responsive behaviors have meaning. It's our responsibility to decipher what is being communicated - an unmet need or a response to a trigger in the environment" (eLearning Participant).

\section{2) Knowledge is power}

Although participants reported they still wanted to have more experience, they did describe feeling less scared, more prepared, comfortable, and confident going into their practicum. They were also able to describe specific strategies they could use to calm a person with dementia who was upset and agitated. This was defined by the research team as 'Knowledge is Power'. Participants had the knowledge and skills to know what behaviours to look for and how to stay safe using techniques learned in GPA. This 'Knowledge is Power' was particularly valuable as all participants were required to take a theory course on cognitive changes within their program and the GPA training reinforced some of the theory while providing opportunities for participants to apply that knowledge. Participants described the knowledge gained. For example, one participant stated,

"I am now confident in my current ability to interact (connect) with people with dementia. I feel that the HCA Program theory (including GPA) and clinical placements have provided me 
with the skills that will enable me to provide gentle and compassionate care to those with dementia" (F2F participant).

While another described how GPA provided them with knowledge, skills, and self-efficacy to provide person-centred care,

"I think GPA was beneficial overall I think it really helped... it made me feel confident and comfortable in situations with ... people who are responsive. Just having those tools with you at all times and knowing that there is something you can do...the care is all the same and the tools are the same, it doesn't change, you learn one thing and it works, makes you just feel comfortable" (eLearning Participant).

This knowledge provides the participants with a sense of power because they understand that they have options in the way the provide care. As described by the following participant,

"All behaviours have meaning so be mindful, more tools in your tool belt, and so I have tools in my tool belt, so it's worth to have knowledge. I am still growing in my confidence everyday it's a work in progress... having a positive attitude and a different approach to it and just not labelling them as a difficult person, keeping my mindset open" (eLearning Participant).

Descriptions of some of the specific strategies learned in the GPA training became evident at the end of this project that highlighted 'Knowledge is Power'. Participants reported the use of eye contact, safe space, open body language, as well as slowing down and backing away for a time period. One participant stated, "I used the "Stop and Go", Validation, employed effective Communication Principles, and respected Personal Space. I did also have to use the Thumb Release (for Grasp Reflex) as well." And another described how they used the GPA skills, "I slowed down and backed away for a few minutes. When I came back, I used a very calm, quiet voice."

\section{3) Paying attention}

Another theme that evolved was that of 'Paying Attention'. Participants described the need to be observant and read the non-verbal cues of the residents. 'Paying Attention' also included the participants getting to know the residents and being attentive. For example one participant stated, "The more you know residents the more you can see that verbal and non-verbal behaviour", while another stated they would be, "Calm, listen and validate feelings try to find the root of the problem..." (eLearning participant). Another participant explained 'Paying Attention' as,

"... to watch and beware of the signs of escalation because it all starts with the non-verbal behaviour and watching visual expressions... I feel from just shadowing that this hasn't happened, some people aren't observing what non-verbal cues a client will be giving you as you walk in the room, you can tell what their mood is, and if you aren't paying attention it can completely go over your head" (F2F Participant).

\section{4) Labelling residents}

A final theme that became evident from the analysis of focus group data was one of 'Labelling Residents', as the longterm care facilities use a system to identify residents who are deemed as having the potential for responsive behaviours. This was something that the participants identified as the 'purple dot' on charts. Participants de-scribed their frustration with such a system as they felt it set up residents to be labelled as "aggressive". For example, one participant remarked,

"For me it feels like residents get signed a purple dot without any sort of deep thought, so they could have one incident where maybe it was triggered by something and of course some people are going to get really upset over something. . . but it doesn't necessarily define them as a person... they cannot control their own care..." (eLearning Participant).

Participants described the stigma that labelling residents had on their ability to provide care. As one expressed, "the purple dot was so broad that it could be physical, like they have punched someone in the face or they have told someone to screw off because they didn't want their care done that day" (F2f Participant). This stigma of the label created anxiety, and fear for the participants about giving care. As recounted by another participant, "... there was a purple dot on my person and [I] was like oh my God, then she slept through the whole thing, so why the purple dot thing?" (F2F Participant). However, the participants recognized why the need for such a system, "to be aware but hopefully it doesn't label to a point where people just don't, you know, label them". One participant's comment clearly illustrated the issue of 'Labelling Residents',

"they get labelled as "difficult" ... but I find that some caregivers are aggressive to the people 
that have been labelled as aggressive, and they get aggressive right back. I think if you go up to them in a gentle, open kind of loving way; that they don't seem to want to attack, if we treat them that way" (eLearning Participant).

\section{Discussion}

The aim of this study was to explore and understand how an educational training program for HCA students prepared them to care for people living with dementia, including the management of responsive behaviours through a transformational learning framework. Researchers described students' experiences after the completion of their clinical practice courses. Prior to taking the GPA training, students did not feel confident and were not able to describe specific strategies for working with people with responsive behaviours. However, results showed how the GPA training provided students with important knowledge and skill to care for residents with cognitive changes, as they felt more prepared. Responses showed participants gained knowledge and understanding of personhood and responsive behaviours as expressions of unmet needs, as well as several evidence-based, effective strategies that they could use to support people with dementia and responsive behaviours. Such findings support previous research where students' preparation in dementia care helped students feel less distress and more prepared. ${ }^{[33]}$ Through GPA training, students transformed their understanding of how cognitive changes in people living with dementia might contribute to the expression of responsive behaviours, helping them to be more empathetic and person-centred. This transformed understanding is congruent with that of what Mezirow $^{[22,23]}$ described as becoming critically aware by considering and revising their beliefs and assumptions.

Regardless of the format in which participants completed GPA, they developed a strong understanding of the concept of person-hood and the etiology of responsive behaviours They described an awareness of their responsibility as caregivers in searching for triggers in the resident's environment, as well as how to use strategies learned in the GPA training such as stop and go, validation, and gentle redirection when a patient with dementia is upset or agitated. Participants were satisfied with the GPA program and expressed that it had prepared them for caring for people with dementia during their clinical placements. These are in line with Matsuda's and colleagues ${ }^{\text {[34] }}$ study, where both nurses and nursing students showed increased confidence in caring for people living with dementia after the completion of a dementia training program. The researchers reported a decrease in the number of challenging interactions between students and residents. Moreover, students gained substantial knowledge and learned the importance of early detection and use of strategies to prevent and/or de-escalate responsive behaviours, with students reporting increased confidence to care for people living with dementia. ${ }^{[34]}$

Overall, consensus from students was that all behaviour had meaning. When students understood the underlying meaning of responsive behaviours and knew communication and interpersonal strategies for de-escalating such behaviours, they were better prepared to ensure the safety of both themselves and people with dementia for whom they are caring. The GPA training helped students move along in the transformational learning process where they moved from just understanding about dementia and responsive behaviours to that of having the confidence and competence to apply this new knowledge into their practice. ${ }^{[22,23]}$ Students reported improved knowledge, self-efficacy, and confidence following the completion of the educational training, but more so after the end of their clinical course experience. Students described, in much more detail, strategies that they either used or could use when caring for residents with responsive behaviours. This is similar to the results of other studies where students' knowledge, confidence, and self-efficacy significantly improved after the completion of dementia training. ${ }^{[19,21,26,34,35]}$

Attaining knowledge is a precursor toward a deeper understanding of why people with cognitive changes respond the way they do. Students need knowledge regarding dementia prior to any experiential, hands-on learning experiences. ${ }^{[21,33]}$ Alushi and Hammond, ${ }^{[36]}$ found a need for appropriate education on care of residents with dementia in undergraduate curricula. However, Harto ${ }^{[20]}$ found knowledge on dementia alone was not enough and suggested that students need a high level of understanding to be effective caregivers for people living with dementia. The GPA training, along with the 270-hour clinical experience offered to students in this study, provided the opportunity to learn about person-centred care while managing responsive behaviours. Students were able to put into practice their newfound knowledge and use strategies in real time to manage potential responsive behaviours that are often seen in people with dementia. The combination of the two components were effective in students' developing deeper understanding by applying what was learned. Students were able to use the learned knowledge from the GPA training, making meaning to guide their action; thus, transforming their learning. ${ }^{[22,23]}$

Having the opportunity to be immersed in the clinical environment offered students time to consolidate what they had learned in the classroom. Other studies on nursing students' preparation to care for people living with dementia have 
shown that students feared the unknown, felt unprepared and inadequate in their clinical experience. ${ }^{[21]}$ While specific education on dementia may have a positive and significant effect on students' attitudes, knowledge, and confidence, the lack of clinical experience after receiving dementia education may delay consolidation of knowledge and skills. ${ }^{[20,21]}$ As this study showed, not only does educational training have a positive effect on students' knowledge, skill, and confidence, but also on their experience in the clinical setting. Post-GPA clinical practicum experience helped to solidify their confidence and competence to care for residents with dementia.

The need to incorporate evidence-based dementia curricula into nursing programs is suggested as an important element for improving confidence of students, as they generally do not feel confident to deliver person-centred care to people living with dementia. ${ }^{[17,20,21,33]}$ The results from this study highlight how GPA dementia training positively impacted students' perceptions, knowledge, and skill over a threemonth period. Overall, these results suggest that GPA is an educational intervention that effectively equips Health Care Assistant students to work with older adults who have dementia and responsive behaviours.

\section{Limitations}

There were some limitations to the study. The participants represented a homogenous sample from one university HCA program. To improve confirmability/generalizability, exploring views of HCA students from other university programs is suggested. Moreover, as part of the HCA program where this study took place, all students were required to complete a theoretical course on care for persons with cognitive challenges prior to taking the GPA training. This may have influenced or improved students' baseline knowledge about general strategies to manage responsive behaviour, although their pre-GPA responses indeed reflected a lack of confidence and a need for knowledge of specific strategies they might use when faced with responsive behaviours in a person living with dementia. Finally, self-selection bias is often an issue when conducting research using convenience sampling. Self-selection bias may have been a limitation as participants who elected to participate (particularly in the focus groups) may found the educational intervention more beneficial and transformative than those who chose not to participate. Nevertheless, the themes we derived from the qualitative responses were consistent and repeated across many of the participants.

\section{Conclusion}

Responsive behaviours in people living with dementia can be difficult for healthcare providers to manage and can be particularly distressing for HCA students. These students, who are young, novice, caregivers providing direct care to people living with dementia are at increased risk of experiencing responsive behaviours. Developing the necessary knowledge and skill to care for people with dementia-related responsive behaviours should occur through specific education on dementia care before students experience their first clinical practicum. Regardless of the delivery used as was done in this study, using an evidenced-based systematic, consistent person-centred approach is likely to benefit both the student and care recipients. The GPA education curriculum provides such an approach and for this reason, should be directed towards health care students early in their programs.

\section{Conflicts of InTERest Disclosure}

The author declares that there is no conflict of interest.

\section{REFERENCES}

[1] Alzheimer's Society of Canada. Rising tide: The impact of dementia on Canadian society: Alzheimer's Society of Canada. Available from: https://alzheimer.ca/en/suroit/Get-involved/Ad vocacy/Latest-info-stats/Rising-Tide

[2] Geda Y, Schneider L, Gitlin L, et al. Neuropsychiatric symptoms in Alz-heimer's disease: past progress and anticipation of the future. Alzheimer's \& Dementia. 2013; 9(5): 602-608. PMid:23562430 https://doi.org/10.1016/j.jalz.2012.12.001

[3] van der Linde R, Dening T, Matthews F, et al. Grouping of behavioural and psychological symptoms of dementia. International Journal of Geriatric Psychiatry. 2014; 29(6): 562-68. PMid:24677112 https://doi.org/10.1002/gps . 4037

[4] Herron R, Wrathall A. Putting responsive behaviours in place: Examining how formal and informal carers un-derstand the actions of people with dementia. Social Science \& Medicine. 2018; 204: 9-15.
PMid:29549870 https://doi.org/10.1016/j.socscimed. 20 18.03 .017

[5] Passmore M, Ho A, Gallagher R. Behavioral and psychological symptoms in moderate to severe Alzheimer's disease: a palliative care approach emphasizing recognition of personhood and preservation of dignity. Journal of Alzheimer's Disease. 2012; 29(1): 1-13. PMid:22207006 https : //doi .org/10.3233/JAD-2012-11142 4

[6] Colenda C, Hamer R. Antecedents and interventions for aggressive behavior of patients at a geropsychiatric state hospital. Hospital and Community Psychiatry. 1991; 42(3): 287-92. PMid:1903126 https://doi.org/10.1176/ps.42.3.287

[7] Brazil K, Maitland J, Walker M, et al. The character of behavioural symptoms on admission to three Cana-dian long-term care homes. Aging \& Mental Health. 2013; 17(8): 1059-1066. PMid:23777187 https://doi.org/10.1080/13607863.2013.807423 
[8] Dewing J. Responding to agitation in people with dementia. Nursing Older People. 2010; 22(6): 18-25. PMid:20632545 https: //doi.org/10.7748/nop2010.07.22.6.18.c7837

[9] Zeller A, Hahn S, Needham I, et al. Aggressive behavior of nursing home residents toward caregivers: A systematic literature review. Geriatric Nursing. 2009; 30(3): 174-87. PMid:19520228 https://doi.org/10.1016/j.gerinurse.2008.09.002

[10] Occupational Safety and Health Administration. Workplace violence in healthcare: Understanding the chal-lenge. 2015. Available from: https://www. osha.gov/Publications?0SHA38

[11] Spencer S, Stone T, McMillan M. Violence and aggression in mental health inpatient units: an evaluation of aggression minimisation program. HNE Handover for Nurses and Midwives. 2010; 3(1).

[12] Jackson D, Hutchinson M, Everett B, et al. Struggling for legitimacy: Nursing students' stories of organisational aggression, resilience and resistance. Nursing Inquiry. 2011; 18: 102-110. PMid:21564391 https://doi.org/10.1111/j.1440-1800.2011.00536.x

[13] Nau J, Halfens R, Needham I, et al. The de-escalating aggressive behavior scale: development and psy-chometric testing. Journal of Advance Nursing. 2009; 65: 1956-1964. PMid:19694859 https://doi.org/10.1111/j.1365-2648.2009.05087.x

[14] Bostrom A, Squires J, Mitchell A, et al. Workplace aggression experienced by frontline staff in dementia care. Journal of Clinical Nursing. 2012; 21(9-10): 1453-1465. PMid:22151034 https: //doi.org/10.1111/j.1365-2702.2011.03924.x

[15] Magnavita N, Heponiemi T. Workplace violence against nursing students and nurses: an Italian experience. Journal of Nursing Scholarship. 2011; 43: 203-210. PMid:21605325 https : //doi .org/10 $.1111 / j .1547-5069.2011 .01392 . x$

[16] Worksafe BC. Dementia: understanding risks and preventing violence. Worker's Compensation Board of Brit-ish Columbia. 2010 Available from: https://www.worksafebc.com/en/resource s/health-safety/books-guides/dementia-understandi ng-risks-and-preventing-violence?lang=en6

[17] Leather P, Zarola A. Violence and aggression management training for trainers and managers: A national eval-uation of the training provision in healthcare settings. 2006. Available from: www.hse.go v.uk/researc/rrpdf/rr440.pdf

[18] Eccleston C, Lea E, McInerney F, et al. An investigation of nursing participants' knowledge of dementia: A questionnaire study. Nurse Education Today. 2015; 35(6): 800-805. PMid:25784500 https://doi.org/10.1016/j.nedt.2015.02.019

[19] Nau J, Halfens R, Needham I, et al. Student nurses' de-escalation of patient aggression: A pretest-posttest intervention study. International Journal of Nursing Studies. 2010; 47(6): 699-708. PMid:19962696 https://doi.org/10.1016/j.ijnurstu.2009.11.011

[20] Harto L. A study of registered nursing students' perceptions of confidence in providing quality nursing care to patients with Alzheimer's disease or other dementia. [Dissertation]. Doctor of Education (Ed.D). 2018. Available from: https://firescholars.seu.edu/coe/2 5

[21] Kimzey M, Mastel-Smith B, Alfred D. The impact of educational experiences on nursing students' knowledge and attitudes toward people with Alzheimer's disease: A mixed method study. Nurse Education Today. 2016; 46: 57-63. PMid:27598794 https://doi.or $\mathrm{g} / 10.1016 / \mathrm{j}$. nedt .2016 .08 .031

[22] Mezirow J. Transformational learning: Theory to practice. New Directions for Adult and Continuing Education. 1997; 74: 5-12. https://doi.org/10.1002/ace.7401
[23] Mezirow J. Transformative learning as a discourse. Journal of Transformational Education. 2003; 1(1): 58-63. https://doi.org/10 $.1177 / 1541344603252172$

[24] Kitwood T. Dementia reconsidered: The person comes first. Philadelphia, PA: Open University Press; 1997.

[25] Hung L, Son C, Hung R. The experience of hospital staff in applying the Gentle Persuasive Approaches to dementia care. Journal of Psychiatric and Mental Health Nursing. 2018.

[26] Pizzacalla A, Montemuro M, Esther Coker E, et al. Gentle Persuasive Approaches: Introducing an edu-cational program on an orthopaedic unit for staff caring for patients with dementia and delirium. Orthopaedic Nursing. 2015; 34(2): 101-09. PMid:25785620 https://doi.org/10.1097/NOR.0000000000000127

[27] Schindel Martin L, Dupuis S. The development and pilot evaluation of an educational program to train long-term care front-line staff in the management of responsive behaviours of a more catastrophic nature associated with dementia: University of Waterloo Murray Alzheimer Research and Education Program. 2005. Available from: https://ageinc.s3.amazonaws. com/uploads/2017/01/GP A-Project-Final-Report-March-2005-rev-nov-1.pdf

[28] Schindel Martin L, Morden P, Cetinski G, et al. Teaching staff to respond effec-tively to cognitively impaired residents who display self-protective behaviors American Journal of Alzheimer's Disease and Other Dementias. 2003; 18(5): 273-81. PMid:14569644 https://doi.org/10.1177/153331750301800510

[29] Schindel Martin L, Gillies L, Pizzacalla A, et al. McLelland V. An education inter-vention to enhance staff self-efficacy to provide dementia care in an acute care hospital in Canada: A nonrandomized controlled study. American Journal of Alzheimer's Disease and Other Dementias. 2016; 31(8): 664-77. PMid:27659392 https://doi.org/10.1177/1533317516668574

[30] Speziale J, Black E, Coatsworth-Puspoky R, et al. Moving forward: evaluating a curriculum for managing responsive behaviors in a geriatric psychiatry inpatient population. Gerontologist. 2009; 49(4): 570-76. PMid:19520841 https://doi.org/10.1093/geront/g np069

[31] Merriam S. Qualitative research: A guide to design and implementation, 2009. San Francisco, CA: Jossey-Bass.

[32] Clarke V, Braun V. Successful qualitative research: A practical guide for beginners, 2013. London: Sage.

[33] Scerri A, Scerri C. Nursing students' knowledge and attitudes towards dementia: A questionnaire survey. Nurse Education Today. 2013; 33(9): 962-68. PMid:23182308 https://doi .org/10.101 $6 / j$.nedt. 2012.11.001

[34] Matsuda Y, Hashimoto R, Takemoto S, et al. Educational benefits for nurses and nursing students of the dementia supporter training program in Japan. PLoS One. 2018; 13(7): e0200586. PMid:30024922 https://doi.org/10.1371/journal . pone.0200586

[35] Mitchell G, McGreevy J, Carlisle S, et al. Evaluation of 'Dementia Friends' programme for undergraduate nursing students: Innovative practice. Dementia (London). 2017; 16(8): 1075-1080. PMid:26979582 https://doi.org/10.1177/14713012166385 89

[36] Alushi L, Hammond J. Evaluation of dementia education programs for pre-registration healthcare students: A review of the literature. Nurse Education Today. 2015; 35(9): 992-98. PMid:25981137 https://doi.org/10.1016/j.nedt.2015.04.006 